2018 AAHKS Symposium

\section{OUTPATIENT JOINT REPLACEMENT: PRACTICAL GUIDELINES FOR YOUR PROGRAM BASED ON EVIDENCE, SUCCESS, AND FAILURES}

Moderator Introduction

R. Michael Meneghini, MD

Indiana University Health Orthopedics, Fishers, IN

Indiana University School of Medicine, Department of Orthopaedic Surgery, Indianapolis, IN

R. Michael Meneghini, MD (corresponding author)

Indiana University School of Medicine, Department of Orthopaedic Surgery

Indiana University Health Orthopedics, 13000 East 136th Street, Suite 2000, Fishers, IN 46037

Phone: 317-688-5980; Fax: 317-678-3222

Email: rmeneghi@iuhealth.org

This is the author's manuscript of the article published in final edited form as:

Meneghini, R. M. (2019). 2018 AAHKS Symposium -- Outpatient Joint Replacement: Practical Guidelines For Your Program Based On Evidence, Success, And Failures - Moderator Introduction. The Journal of Arthroplasty. 
Introduction

Over the past decade and a half, there has been increasing interest in performing

48 primary hip and knee replacement in the outpatient setting [1-20], and rapid recovery

49 protocols have created a natural evolution from the inpatient to outpatient setting.[2, 3, 6 ,

50 10, 21-23] Interest in outpatient arthroplasty also has been fueled by financial

51 considerations including the ability to control costs within the episode of care, the

52 potential for surgeon ownership in ambulatory surgery centers, and the ability for a

53 surgeon to control his or her operating room and surgical care environment more easily in

54 an ambulatory surgery center. [1, 5, 8, 24] Outpatient total joint arthroplasty (TJA) has

55 been successfully performed during the past decade by a select group of surgeons and

56 institutions $[4,22,25,26]$ and success has been attributed to multidisciplinary care

57 coordination, standardized perioperative protocols, discharge planning, and careful

58 patient selection. [2-4, 7, 22, 25, 26] In our own program, these essential elements

59 reported by others, with an emphasis on robust and data-driven patient selection [19], we

60 have continued to increase our percentage of surgeries safely performed in the outpatient

61 setting from $9.2 \%$ in 2015 to $18.7 \%$ in 2018 .

62 The information contained in this symposium provides the basic framework and

63 principles of hip and knee arthroplasty performed in the outpatient setting. The following

64 articles detail the essential concepts to be addressed when considering and ultimately

65 performing outpatient joint arthroplasty, either in the hospital or ambulatory surgery

66 center. Patient selection is considered by many to be the most important aspect of

67 outpatient hip and knee arthroplasty, yet there remains very little data to guide surgeons

68 and institutions in this particular realm. The symposium authors will report an update on 
69 the previously reported Outpatient Arthroplasty Risk Assessment Score (OARA). [19]

70 Symposium authors will also detail the extra considerations and responsibilities of the

71 office staff necessary to conduct outpatient total joint arthroplasty, as well as the unique

72 protocols and pathways for the facilities to consider to perform outpatient total hip and

73 knee arthroplasty. Finally, the difference between outpatient surgical procedure facility

74 setting, whether the hospital or the ambulatory surgery center, will be examined and

75 discussed. The importance of the information contained in this symposium cannot be

76 overemphasized given the forces driving the transition of hip and knee arthroplasty

77 traditionally within the hospital to same day discharge in the outpatient setting. Even the

78 Center for Medicare and Medicaid Services anticipate, even encourage, the shift to the

79 outpatient setting for these procedures by removing total knee arthroplasty from the

80 Inpatient-Only List. [27] Finally, given the importance of this issue, the American

81 Association of Hip and Knee Surgeons released a position statement on outpatient hip

82 and knee arthroplasty in collaboration with the American Academy of Orthopaedic

83 Surgeons, the Knee Society, and Hip Society, which emphasizes the essential elements

84 that emphasize and center on patient safety. [28]

85

86 


\section{$87 \quad$ References}

88 1. Aynardi M, Post Z, Ong A, Orozco F, Sukin DC. Outpatient surgery as a means of cost

89 reduction in total hip arthroplasty: a case-control study. HSS J 10(3): 252, 2014

90 2. Berger RA. A comprehensive approach to outpatient total hip arthroplasty. Am J

91 Orthop (Belle Mead NJ) 36(9 Suppl): 4, 2007

92 3. Berger RA, Jacobs JJ, Meneghini RM, Della Valle C, Paprosky W, Rosenberg AG.

93 Rapid rehabilitation and recovery with minimally invasive total hip arthroplasty. Clin

94 Orthop Relat Res (429): 239, 2004

95 4. Berger RA, Sanders S, Gerlinger T, Della Valle C, Jacobs JJ, Rosenberg AG.

96 Outpatient total knee arthroplasty with a minimally invasive technique. J Arthroplasty

97 20(7 Suppl 3): 33, 2005

98 5. Bertin KC. Minimally invasive outpatient total hip arthroplasty: a financial analysis.

99 Clin Orthop Relat Res (435): 154, 2005

100 6. Dorr LD, Thomas DJ, Zhu J, Dastane M, Chao L, Long WT. Outpatient total hip

101 arthroplasty. J Arthroplasty 25(4): 501, 2010

102 7. Kolisek FR, McGrath MS, Jessup NM, Monesmith EA, Mont MA. Comparison of

103 outpatient versus inpatient total knee arthroplasty. Clin Orthop Relat Res 467(6): 1438,

1042009

105 8. Lovald S, Ong K, Lau E, Joshi G, Kurtz S, Malkani A. Patient selection in outpatient

106 and short-stay total knee arthroplasty. J Surg Orthop Adv 23(1): 2, 2014

107 9. Sculco PK, Pagnano MW. Perioperative solutions for rapid recovery joint arthroplasty:

108 get ahead and stay ahead. J Arthroplasty 30(4): 518, 2015 
109 10. Stambough JB, Nunley RM, Curry MC, Steger-May K, Clohisy JC. Rapid recovery

110 protocols for primary total hip arthroplasty can safely reduce length of stay without

111 increasing readmissions. J Arthroplasty 30(4): 521, 2015

112 11. Weiser MC, Kim KY, Anoushiravani AA, Iorio R, Davidovitch RI. Outpatient Total

113 Hip Arthroplasty Has Minimal Short-Term Complications With the Use of Institutional

114 Protocols. J Arthroplasty, 2018

115 12. Toy PC, Fournier MN, Throckmorton TW, Mihalko WM. Low Rates of Adverse

116 Events Following Ambulatory Outpatient Total Hip Arthroplasty at a Free-Standing

117 Surgery Center. J Arthroplasty 33(1): 46, 2018

118 13. Richards M, Al-Youssef H, Kim JK, Poitras S, Penning J, Beaule PE. An Evaluation

119 of the Safety and Effectiveness of Total Hip Arthroplasty as an Outpatient Procedure: A

120 Matched-Cohort Analysis. J Arthroplasty, 2018

121 14. Kim KY, Feng JE, Anoushiravani AA, Dranoff E, Davidovitch RI, Schwarzkopf R.

122 Rapid Discharge in Total Hip Arthroplasty: Utility of the Outpatient Arthroplasty Risk

123 Assessment Tool in Predicting Same-Day and Next-Day Discharge. J Arthroplasty 33(8):

$124 \quad 2412,2018$

125 15. Kelly MP, Calkins TE, Culvern C, Kogan M, Della Valle CJ. Inpatient Versus

126 Outpatient Hip and Knee Arthroplasty: Which Has Higher Patient Satisfaction? J

127 Arthroplasty, 2018

128 16. Hoffmann JD, Kusnezov NA, Dunn JC, Zarkadis NJ, Goodman GP, Berger RA. The

129 Shift to Same-Day Outpatient Joint Arthroplasty: A Systematic Review. J Arthroplasty

$130 \quad 33(4): 1265,2018$ 
131 17. Courtney PM, Froimson MI, Meneghini RM, Lee GC, Della Valle CJ. Can Total

132 Knee Arthroplasty Be Performed Safely as an Outpatient in the Medicare Population? J

133 Arthroplasty 33(7S): S28, 2018

134 18. Nelson SJ, Webb ML, Lukasiewicz AM, Varthi AG, Samuel AM, Grauer JN. Is

135 Outpatient Total Hip Arthroplasty Safe? J Arthroplasty 32(5): 1439, 2017

136 19. Meneghini RM, Ziemba-Davis M, Ishmael MK, Kuzma AL, Caccavallo P. Safe

137 Selection of Outpatient Joint Arthroplasty Patients With Medical Risk Stratification: the

138 "Outpatient Arthroplasty Risk Assessment Score". J Arthroplasty 32(8): 2325, 2017

139 20. Meneghini RM, Ziemba-Davis M. Patient Perceptions Regarding Outpatient Hip and

140 Knee Arthroplasties. J Arthroplasty 32(9): 2701, 2017

141 21. Hozack WJ, Matsen-Ko L. Rapid recovery after hip and knee arthroplasty: a process

142 and a destination. J Arthroplasty 30(4): 517, 2015

143 22. Berger RA, Kusuma SK, Sanders SA, Thill ES, Sporer SM. The feasibility and

144 perioperative complications of outpatient knee arthroplasty. Clin Orthop Relat Res

145 467(6): 1443, 2009

146 23. Berend KR, Lombardi AV, Jr., Mallory TH. Rapid recovery protocol for peri-

147 operative care of total hip and total knee arthroplasty patients. Surg Technol Int 13: 239,

1482004

149 24. Lavernia CJ, Villa JM. Rapid recovery programs in arthroplasty: the money side. J

150 Arthroplasty 30(4): 533, 2015

151 25. Berger RA, Sanders S, D'Ambrogio E, Buchheit K, Deirmengian C, Paprosky W,

152 Della Valle CJ, Rosenberg AG. Minimally invasive quadriceps-sparing TKA: results of a

153 comprehensive pathway for outpatient TKA. J Knee Surg 19(2): 145, 2006 
154 26. Berger RA, Sanders SA, Thill ES, Sporer SM, Della Valle C. Newer anesthesia and

155 rehabilitation protocols enable outpatient hip replacement in selected patients. Clin

156 Orthop Relat Res 467(6): 1424, 2009

157 27. Yates AJ, Kerr JM, Froimson MI, Della Valle CJ, Huddleston JI. The Unintended

158 Impact of the Removal of Total Knee Arthroplasty From the Center for Medicare and

159 Medicaid Services Inpatient-Only List. The Journal of arthroplasty 33(12): 3602, 2018

160 28. Meneghini RM, Gibson W, Halsey D, Padgett D, Berend K, Della Valle CJ. The

161 American Association of Hip and Knee Surgeons, Hip Society, Knee Society, and

162 American Academy of Orthopaedic Surgeons Position Statement on Outpatient Joint

163 Replacement. J Arthroplasty 33(12): 3599, 2018

164 